\title{
University STAFF: motivation of innovative activities
}

\author{
Alexander Vyzhigin ${ }^{1, *}$ \\ ${ }^{1}$ Moscow Humanitarian University, Moscow, Russia
}

\begin{abstract}
The article researches the motivation and improvement of the innovative activities of faculty by means of implementation of the score-rating assessment of knowledge in the educational process. This research clarified the scientific understanding of the nature of motivation of professors; identified criteria motivating researchers and professors; proposed an innovative method to improve motivated teaching career on the basis of score-rating system of assessment.
\end{abstract}

\section{Introduction}

Research of faculty's motivational problems. To implement quality training of bachelors and masters Significant place should be given to motivation, which serves as an internal driving force for enhancing the professor's professionalism, his self-development and self-realization in professional and educational sphere.

Object of research: innovation activities of faculty.

Subject of research: perfecting of faculty's innovation activities.

Purpose of research: increasing the efficiency of the faculty through the development and implementation of the score-rating assessment ofknowledge in the educational process.

Hypothesis of research: professional and innovative activities of faculty will be effective if:

1) it is reviewed and recognized as the main component of vocational training, providing a focused, motivated collectively worked-out activities;

2) it is organized with innovative approach, implemented through the score-rating system (SRS).

Up to the purpose and hypothesis of research the main objectives of the study have been determined:

- clarify the scientific understanding of the nature of faculty's motivation;

- identify criteria of faculty's motivation;

- offer an innovative method to improve educational activities motivated and based on SRS.

\section{Research and discussion}

Motivation of pedagogical and educational activities: Motivation of education is the common name for the host of methods and means of motivation - processes designed to produce cognitive activity and activize the development of educational content (Gordashnikov V. A., Osin A. Y. Education and health of students of medical college Publisher "Academy of Natural Sciences", 2009)

Motivation is the key characteristic for both professors ( motivation to teach, attitude to professional duties) and students (motivation to learn, inner motivation or self-motivation).

In any activity (including innovative) except for external motivators there IS internal driving force, they have different functions.

Internal stimulus (the need, motive) is seen as the person's need for the implementation of activities, and external (adequate - the subject, the means or the external environment) acts as an incentive, because it means that there is the possibility of its implementation (availability of the desired activity product). In this case the inner stimula is primary, and external objects prompt only if there is an internal driving force.

It can be concluded that any innovative activity must be pragmatic.

Teaching: the work of a professor is a work that belongs to the sphere of the spiritual, intellectual production, which is a large independent work, associated with the preparation of the course and design of the upcoming activities and their organization.

Content of teaching determined by the Federal state educational standards, basic educational programs, textbooks, the material which must be properly restructured and organized.

The elements of the teaching process are object, product and means of teaching.

Object of teaching is an educable person (applicants, students).

Product of teaching is a graduate of the university, which has a certain competence level and demanded by employers (bachelor, master, $\mathrm{PhD}$ ) and the material (training complex, a teaching aid, educational programs, textbooks, monographs) and intangible (know-how in the teaching methods) products of educational process.

Under the competences of bachelor/master should be understandedhe methodologies of action ensuring of

* Corresponding author: vijigin new2000@mail.ru

(C) The Authors, published by EDP Sciences. This is an open access article distributed under the terms of the Creative Commons Attribution License 4.0 (http://creativecommons.org/licenses/by/4.0/). 
productive performance of professional activities. It is the ability of person to put their competencr into practice.

Means of teaching are theoretical and practical knowledge, which should be transmitted to students, as well as a set of actions performed, their ratio and relationship: educational and scientific technologies, innovations, educational and scientific material base.

The specifics of teaching: determined by education, training (not in the new Education Act), the scientific application of existing knowledge, the transfer of theoretical and practical experience to students.

Purpose of teaching in universities: high-qualitaty knowledge production and learning to master the scientific and practical skills, influencing the formation of the future expert intelligence by creating and mastering the methods of teaching.

Motives and motivation of professors to teach: the problem of motivation of professors in modern scientific sources is given a lot of attention. Professor has become a key figure in educationAL reform - both scientist and educator which determines the pace and nature of the modernization and innovation of education. Knowledge about motivation of professors his prestige, competitiveness depends on the quality of educational services provided by them, their demand for professional's market. Unfortunately, the work of people involved in the formation of intelligence level of the country's population, are currently not adequately assessed up to their contribution to this development.

In various universities in Russian Federation independent researchers conducted a survey the purpose of which was to study the professional activities of professors. Based on the data [23], we can conclude that as long as this profession is not adequately paid and will not be motivated and meaningful to society, there will be a problem of the quality of educational services. For professors monetary compensation continues to play a primary role in the very motives of their professional activities.

Motivational core of professors according to research conducted by Yuri Vasilenko E. Welz in Omsk State University in 1999, at the time of the choice of profession was:

- 1 level (defining) - the possibility of self-realization, a prestigious profession, interest in the subject taught;

- 2 level - makes possible to engage in scientific activities, like communication in a creative team, working independent from external factors, mental labor;

- 3 level - enjoy working with the students, the desire to pass on their knowledge to others, the availability of pedagogical skills, material benefits.

It was concluded that professors are more satisfied with the content of work (51\%), mutual understanding with the students (58\%), promotion opportunities (48\%), relationships with colleagues and administration (69 and $75 \%$, respectively), the realization of their abilities and workload (54\%), the ability to make their own solutiontion (48\%), working conditions (45\%) and the possibility of vocational education, and obtaining additional education (42\%); most of them are not satisfied with the salary received at the university. As it is noted by professors, job satisfaction would increase with increasing social status of professor and university science in society. Therefore they want to devote their spare time to the preparation of scientific developments and materials (70\%), professional development (58\%).

As for determining the level of teacher's professionalism there are such factors as basic education-set and its level, experience of pedagogical work, practical experience.

Public assessment of the professor's activity substantially affects the motivational sphere, and, consequently, it's result. Thus, to improve the quality of teaching work, periodic certification of professors with the formulation of the problem, goals and objectives of their activities may have a great influence. Depending on the certification's results and adequate financial assessment should be given. Differentiated payment of professor's work will depend on the quantity and quality of labor.

The problem of faculty's motivation as a psychological and pedagogical problem._Various options for the definitions of "motive" and "motivation" have been considered to many sources; also the main features and criteria of each of the definitions have been identified. Categories "motive" and "motivation" have a wide variety of concepts.

It was held the selection of terms of conceptual and categorical apparatus sorted by reducing the number of occurrences of the above definitions. These are the motivation, need, action, activity.

The research describes the main characteristics of the professional work of professors and their decomposition by type of motivation - external and internal.

External motivation is accompanied by a financial reward, and the internal interest moves to action. According to this external motivation can be dictated from outside, organizing the situation, or from within, controlling emotions, state of behavior (http://yasuper.Net/vidy-motivatsii-i-eeosobeNNosti.html\#ixzz3ZZteCpqU).

While I he research was held there were counted the normalization criteria of calculating motivation.

It has been formulated the rule calculation of normalization criteria motivating conceptual apparatus.

Up to the author, it can be suggested that the implementation by the professor his professional duties, their needs are placed first, followed by stirring, action or activity.

Simply put, it comes down to a simple formula: getting more benefits and comfort with minimum effort and activity.

This conclusion is supported by the actual professional requirements for teaching. Now all the work of the professor is highly regulated by educational standards, main educational programs and numerously regulated, guiding documentation.

Professor, having, for example, the teaching load of 700-900 hours in the school year, haS to spend in average (we assume that in the academic year there are 
of 30 working weeks) from 26 to 36 hours at a rate of 1 week - it is 5-6 days to 6 classes. The amount of time required to prepare for classes is never seriously considered.

Department of Computer Science and Mathematics of Moscow Humanitarian University for a few years, analyzed the time spent by professors to perform educational, methodical and research work. As a result of averaging the values obtained for the 23 professors that extracurricular load is comparable to the number of hours of classroom load, provided that the people are working full time.

Some professors have an increased load of up to 1,25 or 1,5 rates. Many professors of the department are working partly- 0.5 or 0.25 rate. I remind you that the time for a 6-day working week for professors at the rate is about 3 hours teaching load and the same methodology.

Result calculations are stunning. If the teacher is really working on the development and/or correction of the whole educational, methodical, scientific-term documents, the time to rest a day is an average of 6 hours (taking into account the time needed to arrive at work and home). So when then is it possible to do what is regulated by the Degree of the entire document? Only by reducing the time spent on maintenance of the educational process. This can be achieved through the development of various types of training: tests, independent and home work, assignments, and more. And another important point is, oddly enough, to reduce the time to communicate with the careless students. All this can be ordered only through the use of innovation methods of doing and, more importantly, taking into account the results of the learning process, using, for example, score-rating system.

The innovative activity of the professor on the basis of score-rating knowledge assessment system. Previous system of knowledge control in universities contradicts with the modern requirements for the training of qualified bachelors and masters. Its main disadvantage is obvious - it does not contribute to an active and rhythmic work of the students, including the self-studying. Already in the initial courses, students begin to understand that homework is not necessary to take in time, that everything is possible to bring and pass in the last week. This "rush work" not only multiplies the load on the professor and the student at the end of the semester, but also has the effect of "shaky knowledge" of the subject studied and also congestion to the professor.

In addition, the existing system of pedagogical process averages all - and the student who has passed all the control tasks ahead of schedule, and the student who has passed them only to the beginning of the session. Formally, the same time to both categories of students. This final evaluation on the subject does not take into account the "prehistory", it contains a significant element of chance. This practice evolved in disciplines read by the author from 1992 up to the present.

An attempt was made to improve performance on readable disciplines by increasing the motivation of students through the development and implementation of the score-rating assessment of knowledge and quality of work of the students. Rating is a cumulative phase objective assessment of students' knowledge.

Let us consider the basic provisions applicable the score-rating system [2-4].

The rating of the discipline in each semester is carried out on a 100-point scale and the sum of the current estimates: attendance, protection of the results of work performed on a practical training, knowledge on the intermediate control (testing on topics verification work) and the final evaluation at the credit or exam.

To determine the calculated evaluation score, written by a student during the semester and exam. Professor sets boundary points for all types of evaluations, such as «Unsatisfactory» - less than 55 points; «Satisfactory» (credited) - 55 - 75 points; -76 "Good» - 90 points; «Excellent»- 91 - 100 points.

Proposed score-rating system is effective, because:

1) it takes into account student's current academic performance and thus greatly intensifies its work independently;

2) evaluates the student's knowledge more objectively and accurately by using a 100-point scale assessment criteria taking into account the time of delivery of works 3 ) creates the basis for the differentiation of students; 4) obtains detailed information about the activity of each student including his independent and classroom work up to the shedule.

The most important effect of implementation was a significant decrease in time spent through the introduction of strict rules that instantly sobering "relaxed" students.

Up to results from 2005-2006 to the present we can conclude that students themselves were personally convinced of the mutual influence of the current learning by using score-rating assessment on the final grade in the exam week. The result is an increase in the number of students who passed the substantive session on time from $20-40 \%$ to $60-70 \%$.

\section{References}

1. S. Shapiro. Motivation. "GrossMedia" (2008)

2. A. Vyzhigin, Bulletin of the Moscow State Academy of Instrument Engineering and Informatics, 9, 128-131 (2007)

3. A.Y. Vyzhigin, J. Schipin. Some aspects on the perfection-vaniyu educational process at the university. In XI collection of scientific papers (Moscow,: 2008)

4. A.Y. Vyzhigin, J. Schipin. Ways to improve the quality of education, enforcement process and objectivity of its performance in the Moscow humanitarian-rated university in the new realities of society. In Proc. of the All-Russian scientificpractical conference with international participation Information technology to provide a new quality of higher education (Moscow, 2010) 